\title{
Educational design and networked learning: Patterns, pattern languages and design practice
}

\author{
Peter Goodyear \\ University of Sydney
}

\begin{abstract}
There is a growing demand for advice about effective, time efficient ways of using ICT to support student learning in higher education. This paper uses one such area of activity - networked learning - as a context in which to outline a novel approach to educational design. The paper makes two main contributions. It provides a high level view of the educational design problem space. It then introduces the patterns based approach to educational design. While other professional communities, particularly in software engineering, have been developing patterns based approaches to sharing and re-using design experience, this paper goes back to the original conceptions of participatory design that informed Christopher Alexander's early work on patterns and pattern languages. In particular, it makes connections between the technicalities of design and the central place of values. A patterns based approach can help with encoding, sharing and using knowledge for educational design. But it is also a powerful way of connecting educational values and vision to the details of the tasks, tools and resources we offer our students.
\end{abstract}

\section{Introduction}

This paper outlines a novel approach to thinking about problems of educational design. It uses the specific context of networked learning in higher education to make and illustrate the argument, though it is likely that the range of learning situations in which the approach is useful is actually much wider than this. Clarifying the nature of educational design for networked learning is a major theme within the paper. For now, a working definition will be useful. I take 'educational design' to be the set of practices involved in constructing representations of how to support learning in particular cases. This distinguishes design from development the practices of turning these representations into real support for learning (materials, task specifications, tools, etc). It distinguishes design for particular educational applications from the broad consideration of learning in general. It focuses on practice rather than theory, while 
recognising that practice embodies experiential and theoretical knowledge. Within this framework, it can be seen as a reworking of instructional design, but without the narrow pedagogical repertoire that the term 'instruction' is often taken to connote.

Why should we treat educational design as a problem worth attention; one meriting analysis and new conceptual resources? It would not be reasonable to see it as a problem of this magnitude if we could show that, by and large, existing practices led smoothly to optimal learning outcomes. In higher education there is little reliable research evidence on this matter. However, the recent actions of many universities - expanding their capacity to support academic staff in their use of new technologies - speak loudly. So too do sales of books offering advice on the use of ICT for teaching and learning (e.g. Laurillard, 2001; Salmon, 2000, 2002). There is a substantial unmet demand for usable forms of guidance. In general, the demand from academic staff is for help with design - for customisable, re-usable ideas, not fixed, pre-packaged solutions. However, demand is also expressed in ways which emphasise academics' strong sense of being time-poor. There is no visible demand for complex methodologies, approaches which require substantial revision of existing work practices, or methods which require mastery of complex skills or specialised language. One should not mistake demand for need. Anyone offering help to academic staff, such as those who want to make better use of ICT in their teaching, is well-advised to start with demand but have some sense of underlying need. Sustainable support for educational development depends upon having a roadmap however sketchy - that links current demands for support to an analysis of how longer term needs will be articulated and met.

It is with this sense of current context that I offer the design approach presented here. It is rooted in a conception of what many teachers in higher education are demanding now - time-efficient methods of supporting successful learning (conventionally defined) - but with an eye to the future. It is not future proof. Rather, it combines an openness about the concrete implications of technological change with a set of values about 'good learning'.

\section{Networked learning}

The terms e-learning, web based learning and online learning now have wide currency in education. I use the term networked learning to mean a distinctive version of these approaches. I define networked learning as:

learning in which ICT is used to promote connections: between one learner and other learners; between learners and tutors; between a learning community and its learning resources (Goodyear, Banks, Hodgson \& McConnell, 2004). 
Some of the richest examples of networked learning involve interaction with online materials and with other people. But, in my view, use of online materials is not a sufficient characteristic to define networked learning. Human-human interaction, through computer mediated communication or $\mathrm{CMC}$, is an essential part of networked learning. Networked learning is not necessarily distance learning. It may well involve some face to face interactions, whether or not these are supported by the use of ICT. The important element is connectedness. As time goes by, these connections move with fluidity across the co-present and the distributed, across a variety of media, and with various degrees of time shifting (synchronous, asynchronous, both). The point of mentioning ICT in the definition of networked learning is not to single out ICT enabled learning as special or valuable in itself. Rather, it draws attention to the need for our educational arrangements to become even more flexible - reflecting increasingly fluent use of media and communications methods and novel distributions of collaborative activity and relationships.

The pedagogies of networked learning, naturally enough, emphasise the potential benefits of learning through collaboration with others - whether through online discussion, argumentation, group based investigations, apprenticeship, community action or other forms of joint work (Goodyear, 2002a; Jonassen \& Kwon, 2001; Koschmann, 1996; McConnell, 2000). But there is often a gap between teachers' hopes and educational outcomes, such that it is becoming common to read evaluation reports and research studies which describe teacher disappointment and/or student frustration (Hara \& Kling, 1999; Jones \& Asensio, 2002; Jones, Asensio, \& Goodyear, 2000; Romiszowski \& Mason, 2004). The variability in documented outcomes is, at least in part, due to variation in the quality of teachers' design activity. Successful networked learning depends, to a considerable extent, on well-targeted effort at design time - designing good learning tasks, ensuring good access to robust and appropriate technology, and helping create a convivial learning culture. Recognition of the importance of educational design has led to the production of books and other resources which are intended to support the teacher's design activity (Goodyear, 2001; Salmon, 2000, 2002; Stephenson, 2001). Although such resources have generated positive feedback, we know little about how they are actually used in practice and even less about how well they act as conduits for either research based or experiential design knowledge.

\section{Conceptualising educational design}

The field of educational technology has built up considerable experience of using structured design methodologies, especially in the production of interactive, individualised, computer based learning materials or courseware (de Jong \& Sarti, 1994; Goodyear, 1997; Jonassen, 1988; Naidu, 
1993; Pirolli, 1991; Reigeluth, 1999; Spector, Polson, \& Muraida, 1993; van Merrienboer, 1997). However, there are few examples of successful attempts to deploy such methodologies in the area of networked learning. Rather, the tendency has been for leading writers in this field to position the problem of educational design at the levels of either broad pedagogy and philosophy (e.g. McConnell, 2000) or specific pedagogical techniques (e.g. Salmon, 2000; 2002). The middle ground is the difficult territory in which philosophy and pedagogical tactics have to be aligned. It is a space in which the problems of design can be complex, and can be especially demanding for those who are new to networked learning.

Figure 1 helps tease out the separate layers and components of the educational design problem space and identify some of the key interrelationships.

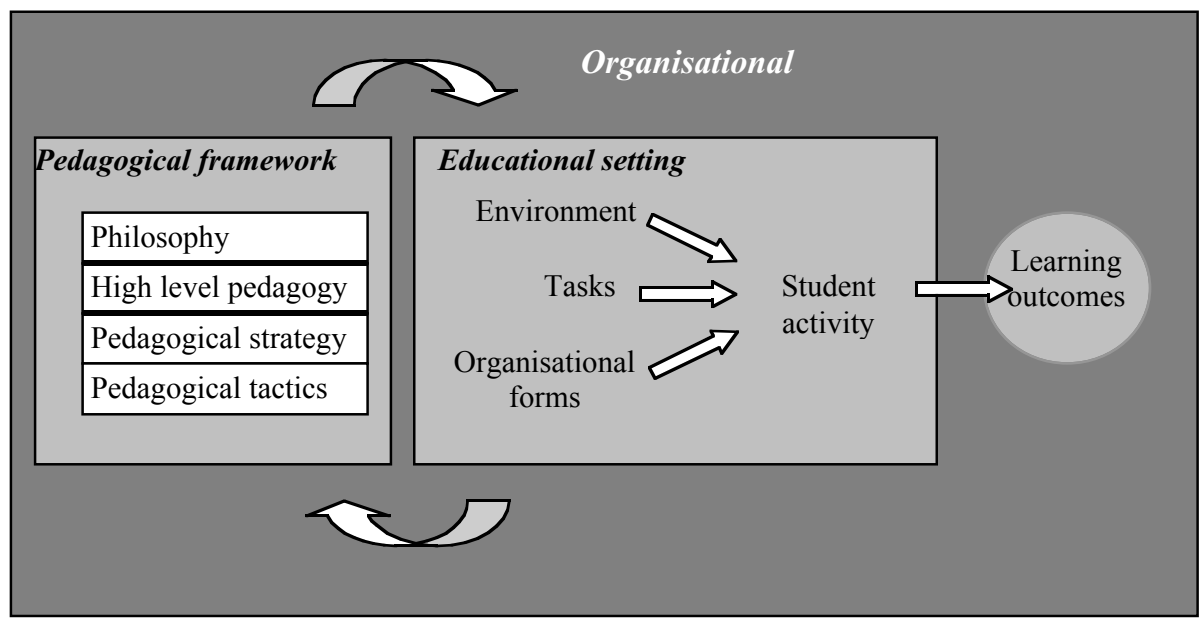

Figure 1: Conceptualising the problem space of educational design (adapted from Goodyear, 1999)

Figure 1 falls into three parts. On the left hand side is a 'pedagogical framework'. It needs to be understood in relation to concrete educational activity in a real world setting. On the right hand side of the figure is such an educational setting. This is a way of describing the real world, concrete activities, processes, people and artefacts involved in a learning activity. Both the pedagogical framework and the educational setting exist within an organisational context, such as within a university, a corporation or a virtual learning institute. The organisational context exerts its influence mainly by conditioning (a) the design and management of the educational setting and (b) the processes through which a pedagogical framework feeds into the design and management of an educational setting. 
The pedagogical framework is a loosely coupled structure in which hierarchical relations can be made between:

- pedagogical philosophy (how we think people learn, what knowledge consists of, how we think people should be treated, etc.),

- high level pedagogy (broad approaches such as problem based learning, cognitive apprenticeship, collaborative knowledge building),

- pedagogical strategy (eg. the use of an online debate) and

- pedagogical tactics (the detailed methods we use to set tasks for students, encourage their participation, offer guidance and feedback, etc).

\section{Pedagogical philosophy}

This layer of the pedagogical framework is composed of a number of sets of beliefs: about the nature of knowledge and competence, about how learning occurs, about how people should and should not be treated, etc. The flavour of this element is best shared through giving some examples. For instance, we might distinguish between instructivism and constructivism as approaches to the design of educational interventions. Or we might distinguish between positivism, phenomenology and realism as epistemological positions. In many cases of educational design or course development, pedagogical philosophy is left implicit or is only rarely discussed, or is held to be too remote from the hard day to day problems of making an educational innovation work to justify spending time on it. Deep and unexplored philosophical differences within the team setting up a new course can lead to fatal divergence in the day to day operational work. It is not uncommon to find some members of a team believing that learners are poor at organising themselves and learn best by being fed information in small amounts, while other members of the team want to promote active, student managed learning. The sooner such discrepancies are found, discussed and reconciled, the less likely is catastrophic failure.

\section{High level pedagogy}

This layer is concerned with the concrete instantiation of philosophical positions in the context of creating a new educational setting. At a philosophical level, someone might say 'I see great advantages in using a Cognitive Apprenticeship approach'. When one makes a commitment to using a Cognitive Apprenticeship approach in a specific educational setting, then one is in the realm of high level pedagogy. There are many candidate forms of high level pedagogy and not all would have the same scale, scope, complexity or coherence. Claims might be made for such things as 'guided discovery learning', 'problem based learning', 'programmed learning', or 'computer supported collaborative learning'. 
From the point of view of their place in the framework, the important thing is that they are at a level of abstraction which is intermediate between philosophy and action. They are a way of turning a philosophical position into a space of commitments and possibilities. A high level pedagogy does not contain direct prescriptions for action, but it puts some forms of possible action into the foreground and others into the background.

\section{Pedagogical strategy}

In contrast, pedagogical strategy is directly concerned with action. A strategy is a broad brush depiction of plans - of what should be done to achieve certain objectives. Strategy needs to account for uncertainties; a good strategy will plan for alternative ways of reaching the objectives. The word 'strategy' has lost some of its military origins, such that it is commonly used in business or the management of universities. But it still carries implications of outsmarting the opposition, or, in the case of pedagogical strategy, of outwitting the learner. It implies that the educator will stay at least a couple of mental steps ahead of the learner and will not be too surprised by what the learner actually does. These resonances are unfortunate. In the networked learning context at least, we rarely subscribe to philosophies which make the learner a pawn in our chess game. So what we mean by strategy is actually something more open, cooperative and egalitarian. Its main purpose is communicative - it supports a description of actions and intentions at a level which hides confusing details. This description of actions and intentions may be constructed for the benefit of members of a course team. It may also be constructed for the mutual benefit of learners and their teachers. In both cases, the point is to promote a shared understanding of intentions and permit coordinated action.

\section{Pedagogical tactics}

The only difference between pedagogical strategy and pedagogical tactics is one of grain size. Tactics are the detailed moves through which strategy is effected. Take an example from networked learning. A team of tutors, acting as conference moderators, might agree to adopt a strategy which is intended to encourage all the learners to participate in a conference. This strategy might involve a number of tactics - including writing an encouraging, positive response whenever a learner makes a contribution to the conference; providing examples of valued kinds of contribution; posing stimulating and non-threatening questions to the group; writing private emails to 'lurkers' to encourage them to participate; rewarding contributions to the conference through the assessment system, etc. In contrast, a team of tutors might decide that it is more important to promote an online debate of high academic quality than to ensure that all the learners participate. Many of the tactics they use would be different: 
writing critical responses that challenge sloppy thinking or unsupported claims in a learner's contribution; exemplifying fine academic writing and argumentation; rewarding academic content rather than social contribution through the assessment system, etc.

Does strategy determine tactics? Not always. A rational planning model would encourage us to derive high level pedagogy from philosophy, strategy from high level pedagogy, and tactics from strategy, through some process of top down inference. Life is rarely so simple. Indeed it is not uncommon to find strategy which is really emerging from tactics - thus strategy becomes a way of describing the common threads woven by intuitive tactical activity. Emergent strategy is still useful. Its articulation can serve the coordination and communication functions outlined above and help turn intuitive action into something more reflective, self aware and discussible.

\section{The internal structure of the pedagogical framework}

Figure 1 partitions the pedagogical framework in two different ways. First, the 'philosophical cap' is separated from the other three layers. This division is referred to in the description of high level pedagogy (above). It is a division between (a) a set of general philosophical positions which are independent of any one instance of a real world educational setting and (b) a set of commitments (high level pedagogy, strategy and tactics) specific to one instance of a real world educational setting. Second, the two upper layers can be described as 'declarative' or 'conceptual' while the two lower layers are 'procedural' or 'operational'. This distinction touches on both the form in which real world descriptions of the elements are given and the nature of the activity which surrounds those descriptions. Philosophical positions and high level pedagogy can be described in ways which are not prescriptive of action. The descriptions contain statements of fact or belief they may sketch the nature of a problem and outline the resources available for its solution. But they will not specify exactly what should be done. Such prescriptions for action are to be found in descriptions of strategy and tactics. These do need to contain well-formed specifications of the action that should be taken to achieve certain objectives given certain conditions.

A final point to be made about the internal structure of the pedagogical framework is that the four elements need not be tightly coupled. Indeed the real world practices of educational innovators are sufficiently undisciplined that we should say the elements are 'loosely coupled' (at best). Loose coupling is both real and advantageous. It reflects the need to work with underspecified conceptual entities, particularly in the early stages of design and course development. One can become clearer about the nature of what one is trying to do once one has made commitments in 
doing it. Thus, it is hard to make a case that the consequences of choices in one layer of the pedagogical framework have clear, precise implications for activity in another layer. It is not a deductive process or one that can readily be automated (c.f. Tennyson, 1994). But neither are the layers free floating. Some degree of coupling is important, in order that we can manage a satisfactory degree of alignment between philosophy, general pedagogical approach, strategy and tactics (Biggs, 1999). Moreover, external forces (such as quality assurance reviews) cause us to account for our activity and intuitions in rational terms: high value is placed on coherence. Cooperation within a course team, and between learners and teachers, depends on mutual intelligibility - our intentions and actions have to be sufficiently coherent to be understood. The loose coupling of elements gives space within which we can be both disciplined and creative, listen to our instincts and make them accountable to others.

On the right hand side of Figure 1, we see a concrete educational setting - a situation in which the predispositions and methods in our pedagogical framework become realised. The design focus is on the tasks we set students, on the physical/digital resources that constitute their learning environment and on the social relationships that constitute their learning community.

\section{Educational setting}

There is no reason to impose limits on the scale of the learning activity or educational setting as a conceptual entity. In some cases, the educational setting may involve (say) 10 learners, a single task, and an hour of learning activity. For others, educational settings might more typically involve hundreds of learners working on multiple tasks over several months. A key feature of an educational setting is that it is of an appropriate scale to design and manage. Indeed, it exists primarily as an artefact or system to be designed and managed. It is artificial and constructed, not a set of naturally occurring phenomena whose properties, relationships and boundaries have to be discovered.

The educational setting is a way of representing the coming together of tasks, activities, environment and people. The distinction between tasks and activities is necessitated by two factors: the strengthening influence of so called constructivist approaches to learning and the high value placed on learner managed learning.

\section{Educational design: tasks, environment and organisational forms}

Detailed educational design involves three kinds of work. The first is concerned with the design of good learning tasks. A learning task is a specification for learner activity. Its design draws on the best of what we 
know about how people learn, on a deep knowledge of academic subject matter and/or vocational competences, and on knowledge of the learners. Essays, laboratory exercises, a structured discussion session or debate, a diagnostic exercise, a topic to research, an artefact to build, a program to write - all these are examples of kinds of learning task. A task needs to be sufficiently well-specified that the chances of a learner engaging in unproductive activity are kept within tolerable limits. Its specification may also need a degree of openness in order to meet variable learner needs and initiate a creative response.

The second kind of work is the design and management of the learning environment. This term is very heavily used in the educational literature yet there are surprisingly few clear definitions of the term and there are several quite different common usages. In this paper, I use the term to mean the physical/digital environment within which learners work. It includes everything from paper and pen to textbooks, computers, the Internet and all its online information resources. The important point here is that learning is severely constrained by the learning environment. Part of the point of educational design is to ensure that more flexible access to learning opportunities is accompanied by appropriate redesign of the learning environment.

The third kind of work focuses on the social rather than the physical environment. We know that learning is both physically and socially situated - that what learners do and what they achieve is in part conditioned by inter-personal relationships, culture and society. While educational design should not attempt to 'create' social relationships, it can (and should) try to create conditions which are supportive of the evolution of convivial learning relationships. Thus, educational design is not just concerned with well-designed tasks and the physical resources needed for learning - it also needs to work on the 'organisational forms' (classes, study groups, project teams, roles, etc) from which learners create their learning relationships.

\section{Learning activity}

The French ergonomist Alain Wisner makes the important distinction between 'task' and 'activity' (Wisner, 1995). Tasks are what managers set they are the prescribed work. Activity is what people actually do. Educators set tasks. Learners interpret the specifications of the task. Their subsequent activity is a more or less rational response to the task, shaped and constrained by all the other tasks they have to face, all the other calls on their time, and their experiential knowledge of what their educators actually value. It is perfectly legitimate for activity to be different from the task which initiated it. If we want learners to take more responsibility for 
their own learning, we have to rely on them to make their own interpretations of learning tasks. We also have to recognise that learners are busy people and learning is only one of the things they have to fit into the day. Like all busy people, successful learners know how to cut corners how to satisfice a learning task.

\section{Task, activity, environment}

A consequence of accepting the legitimate distinction between task and activity is that we should design the learning environment so that it is compatible with activity rather than task. This claim is crucial to user centred educational technology. In the world outside education, good software systems are built around a proper understanding of how people actually do their work - rather than on the basis of a manager's view of how the work should be done. If it is possible to construct the environment so that it encourages real world activity which is close to the task as set, so much the better. But technology which enforces an unacceptably restricted interpretation of the task will be rejected by its intended users. Understanding what learners actually do is a cornerstone of good design. (That is why we need an ergonomics of learning environments - an applied science of the relations between workers/learners and their environment.)

Overall, the main claim for Figure 1 is that it helps separate and relate the abstract and the concrete, the general and the specific, beliefs and actions. It is a way of depicting the problem space of educational design that can help describe and improve the practice of educational design.

\section{Educational design in practice}

To get a better understanding of how educational design can best be supported and improved, we also need to have some clear ideas about educational design in practice. There are many more normative models for educational design than there are accounts of actual design activity (Hoogveld, Paas, Jochems, \& van Merrienboer, 2002). Similarly, there are more normative models for online teaching than there are empirical studies of online teaching in action (Goodyear, 2002b).

What we can reasonably infer from the research is that educational design for networked learning - as carried out by the individual teacher in higher education - is typically a process extending over a period from a few hours to a small number of days, and involves several iterations around a cycle of articulating design goals (What am I trying to achieve here?) and educational design commitments (What will I ask the students to do? How will I group them? What reading material will they need? etc). Within this process, it is common for the designer to make provisional commitments 
(How do I know what I think until I see what I've designed?) and to backtrack. It's a fluid process, involving a conversation between the pedagogical beliefs, knowledge and intentions in the mind of the teacherdesigner and (provisional) design commitments. The design commitments are mostly made in the online space: draft instructions for the students, allocation of students to discussion groups or project teams, placing reading lists and links to e-journals in convenient locations, etc. For increasing numbers of teachers in higher education, this iterative design work takes place using a learning management system or virtual learning environment, such as WebCT or Blackboard.

Depending on local arrangements and practices, this may mean their design work is further supported by templates, examples of designs used by others, resources and methods used in previous years, etc. They may also have access to external example designs, such as those provided on the 'Learning Designs' website at the University of Wollongong (Oliver et al., 2002). (See http: / / www.learningdesigns.uow.edu.au/)

What they are unlikely to have is a set of example designs, or guidelines for design, structured to match the kind of arrangement depicted in Figure 1. That is, the resources available to the teacher engaged in educational design are (a) hard to relate to one another, and (b) hard to locate in relation to a particular pedagogical framework. Moreover, (c) it is unusual to find examples and templates constructed in such a way that they capture, and distil the practical implications of, research based knowledge or (d) sit comfortably with the iterative nature of design practice.

\section{Design patterns and pattern languages}

The remainder of this paper introduces the idea of design patterns and pattern languages for networked learning. The claim is, that this patterns based approach has a good deal to offer educational design, particularly in relation to:

- Providing the teacher-designer with a comprehensive set of design ideas

- Providing these design ideas in a structured way - so that relations between design components (design patterns) are easy to understand

- Combining a clear articulation of a design problem and a design solution, and offering a rationale which bridges between pedagogical philosophy, research based evidence and experiential knowledge of design

- Encoding this knowledge in such a way that it supports an iterative, fluid, process of design, extending over hours or days. 
The original ideas for design patterns and pattern languages come from the writings of Christopher Alexander on architecture and town planning - see, for example, Alexander (1979) and Alexander et al. (1977). Alexander's intention was to democratise architecture and town planning by offering a set of conceptual resources that ordinary people could use in (re)shaping their environment. His work provides a principled, structured but flexible resource for vernacular design. In my view, he strikes the right balance between rigour and prescriptiveness - offering useful guidance without constraining creativity and providing helpful foci for design. His approach is also supportive of a shifting of design power from technical specialists to those who inhabit educational spaces - teachers and learners.

The notion of design patterns has been picked up more recently within the field of software engineering - where it has been used to capture and share aspects of software engineering experience and as a way of representing successful models for the implementation of information systems (see, for example, Gamma, Helm, Johnson, \& Vlissides, 1995). Teachers of software engineering have also been experimenting with the idea of pedagogical patterns and educational technologists have been trying to apply a patterns based approach to working on problems such as learning object descriptions, inter-operability, learning management standards, etc. (Avgeriou, Papasalouros, Retalis, \& Skordalakis, 2003; Eckstein, Marquardt, Manns, \& Wallingford, 2001; Frizell \& Hubscher, 2002a, 2002b; Goodyear, Avgeriou et al., 2004; Lyardet, Rossi, \& Schwabe, 1998).

Design patterns have a number of qualities which, in combination, give them the potential to be a useful way of sharing experience in the field of networked learning. A pattern is a solution to a recurrent problem in a context. In Alexander's own words, a pattern

describes a problem which occurs over and over again in our environment, and then describes the core of the solution to that problem, in such a way that you can use this solution a million times over, without ever doing it the same way twice (Alexander et al., 1977, p.x).

Context is important in helping constrain and communicate the nature of both problem and solution. Describing the context for the problem and its solution avoids over generalisation. In addition, patterns should also teach. They should be written in such a way that they help the reader understand enough about a problem and solution that they can adapt the problem description and solution to meet their own needs. The rationale for the pattern helps with this teaching or explanatory function. Ideally, the name of the pattern should crystallise a valued element of design experience and help relate it to other design elements such that we can create and use a pattern language. The use of patterns, then, can be seen as a way of 
bridging between philosophy, values, theory, empirical evidence and experience (on the one hand) and the practical problems of design.

Alexandrian patterns have the structure shown in Figure 2. (See for example, Alexander et al, 1977, x-xi.)

A picture (showing an archetypal example of the pattern) [easier in architecture than networked learning]

An introductory paragraph setting the context for the pattern

(explaining how it helps to complete some larger patterns)

(to mark the beginning of the problem)

A headline, in bold type, to give the essence of the problem in one or two sentences

The body of the problem (its empirical background, evidence for its

validity, examples of different ways the pattern can be manifested)

The solution, in bold type. This is the heart of the pattern - the field of

physical and social relationships which are required to solve the stated

problem in the stated context. Always stated as an instruction, so that you know what to do to build the pattern.

A diagrammatic representation of the solution

$\diamond \diamond$

(to show the main body of the pattern is finished)

A paragraph tying the pattern to the smaller patterns which are needed to complete and embellish it.

Figure 2: the structure of a typical Alexandrian pattern

An example pattern relating to networked learning is given in Figure 3. The example is taken from a set of patterns developed to represent the pedagogical techniques for online learning summarised and popularised by Morten Paulsen (Paulsen, 1995). These techniques cover 'one alone', 'one to one', 'one to many' and 'many to many' scenarios. The 'many to many' techniques are: Discussion groups; Debates; Simulations or games; Role plays; Case studies; Transcript based assignments; Brainstorming; Delphi techniques; Nominal group techniques; Forums; Project groups; Joint programme and Joint cohort discussions and Visitor experts.

What the example in Figure 3 begins to convey is a sense of how design patterns can work as a method of encapsulating design experience, educational values and research based ideas, rendering them available for re-use in concrete design problems.

But design patterns on their own are rather hard to evaluate and to use. They gain a great deal of meaning and strength from their position in a 
structure, and especially a sequence, of other patterns. Alexander's seminal contribution consisted of 253 patterns, ranging in scale from an INDEPENDENT (geographical) REGION to an ORNAMENT. He called the whole assemblage a pattern language, but also used smaller pattern languages for specific projects (such as building a porch - for which he provides a pattern language consisting of just ten patterns).

Thinking in similar ways about the design space of networked learning, one can advance some tentative proposals about an equivalent pattern language. What would be the largest pattern, equivalent to Alexander's 'Independent region'? I suspect it would be a Course, or Program of study. This is the largest entity which can be designed. At smaller scale levels there are the building blocks of a course, however one labels them in one's own system or institution - Study unit, Module, etc. Then there are the kinds of pedagogical technique catalogued by Paulsen: Discussion group, Debate, etc. Within these are smaller pedagogical tasks, smaller organisational forms, as well as the tools and artefacts with which we populate the learning space.

\section{Discussion group}

This pattern is mainly concerned with the establishment of appropriate organisational forms for knowledge sharing, questioning and critique. It is a way of helping implement the patterns LEARNING THROUGH DISCUSSION, COLLABORATIVE LEARNING and NETWORKED LEARNING PROGRAMME.

Discussion groups are the most common way of organising activity in networked learning environments. The degree to which a discussion is structured, and the choice of structure, are key in determining how successfully the discussion will promote learning for the participants.

Discussions can be relatively structured or relatively unstructured, and they may also change their character over a period of time. It is not uncommon for a teacher to set up a discussion in quite a formal or structured way, and for the structure then to soften as time goes by - for example, as the participants take hold of the conversation, opening up and following new lines of interest.

The structure of a discussion should be such that it increases the likelihood of:

a. an active and substantial discussion, with plenty of on task contributions

b. the students coming away from the discussion with a good understanding of the contributions made 
c. contributions being made by all members of the group and 'listened' to by all other members of the group.

Unstructured discussions run the risks of (for example)

- not getting going properly within the time available

- dissipating into a number of loosely related strands that fail to engage effectively with subject being studied

- dissolving into monologues or two way conversations that fail to involve the whole group (Wertsch, 2002).

Pilkington \& Walker (2003) have demonstrated the value of assigning explicit group roles in online discussion groups. Some writers, for example, McConnell (2000) are not sure about the validity of the teacher setting specific structuring devices, preferring to make the group itself responsible for determining how it wants to discuss things, or carry out its work more generally.

Therefore:

Start any online discussion by establishing its structure. Make the rules and timetable for this structure explicit to all the members of the group. Where there is little time available to the group for the discussion, and/or the members of the group are inexperienced at holding online discussions, the teacher/facilitator should set the structure. Where the students are to set their own structure, the teacher/facilitator should give them support and ideas about how to do this, and encourage them to do so in a fair and timely way.

Patterns needed to complete this pattern include: DISCUSSION ROLE, FACILITATOR, DISCURSIVE TASK

Figure 3: Design pattern for discussion group

Forming a pattern language for networked learning involves painstaking, iterative work, travelling in two directions. From the bottom up, one can sketch individual design patterns, to capture recurrent problems and solutions from our collective experience as networked learning practitioners, interpreting these also through the lens of research based evidence and theory. From the top down, one can try to structure the problem space of design, scoping out the largest and smallest patterns, and sketching relationships between patterns (written and as yet unwritten). Neither approach is sufficient on its own and each can lead to contradictions and problems for the other - hence the need for iteration, revision, patience and a tolerance of ambiguity. 
Table 1: Patterns for networked learning

\begin{tabular}{|c|c|c|}
\hline Tasks & Organisational Forms & $\begin{array}{c}\text { Learning environment } \\
\text { (tools, resources) }\end{array}$ \\
\hline Discuss & Dyad & E-print \\
Debate & Triad & E-journal \\
Brainstorm & T-group & Virtual library \\
Investigate & Learning set & Chat room \\
Critique & Tutorial group & Whiteboard \\
Assess & Seminar group & Shared folder \\
Summarise & Whole class & Wiki \\
Solve puzzle & cohort & Virtual café \\
Write essay & Project team & Portal \\
Develop tool & Roles: & Textbook \\
Memorise & Summariser & Study bedroom \\
& Motivator & \\
\hline
\end{tabular}

Table 1 gives a list of some candidate patterns for networked learning. There is no suggestion that this is a complete list. The patterns are structured according to whether they are mainly concerned with tasks to be set for the students (column one), ways of organising students into groups and/or specific roles (column two), or the tools and resources that need to be made available in the networked learning space or in the student's learnplace (column three). Note that patterns can also integrate elements across two or three of these areas.

Figure 4 shows how patterns can be combined into a pattern language for a specific kind of networked learning activity - in this case, borrowing again from Paulsen's pedagogical technique of 'debate'.

Figure 4, like Table 1, is structured according to tasks, organisational forms and tools / resources. The sequence of tasks needed to constitute a debate is given in the left hand column. Roles are listed in the centre, with links showing connections between roles and tasks. In the right hand column are some options for appropriate online technology and resources. Each of the elements in the figure is a pattern. Each is simply described using the formalism shown in Figures 2 and 3. Each makes sense individually but also when combined in the structure - the pattern language - shown in Figure 4.

\section{Concluding comment}

Designing for networked learning in higher education is not easy. We know very little about how teachers in higher education actually engage in 


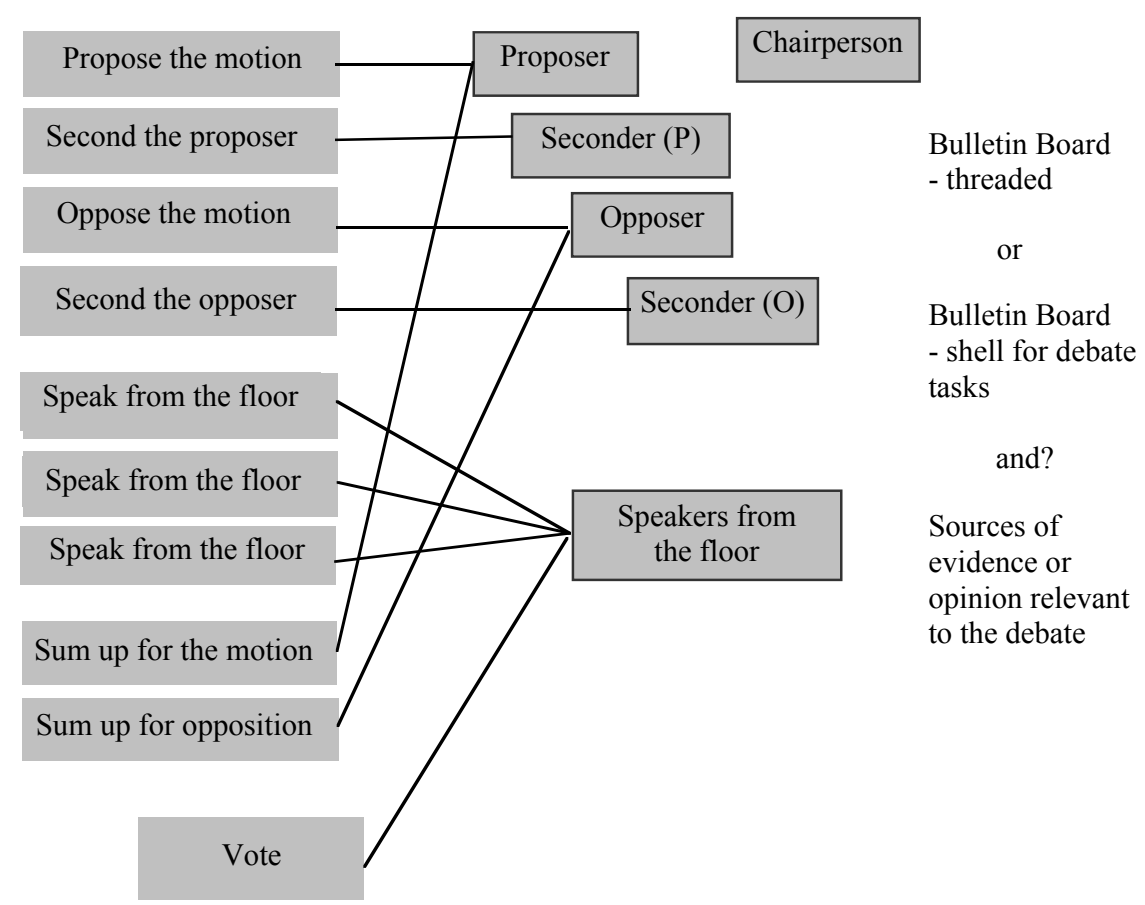

Figure 4: Pattern language for 'debate'

design work and we are probably too ready to generalise from our own activity. However, what we do know about the practices and demands of educational design suggests that our ways of representing and sharing design experience - mainly through texts - need improvement. This paper has sketched an approach, using design patterns, which has potential to capture usable design knowledge, build bridges between practical problems and research based evidence, and help designers see both the wood and the trees when they are engaged in design work. Much more needs to be done before we have a robust and shareable pattern language for networked learning, but this paper represents a milestone along the way.

\section{Acknowledgements}

I am grateful for the opportunity of developing some of these ideas with colleagues in the E-LEN and TELL projects, funded by the European Union. I am also grateful to the University of Sydney for financial support through its Sesquicentenary R\&D scheme. This article is a major revision of 
a paper presented at the ASCILITE conference in 2004. It has benefited from comments by participants in the conference as well as from feedback from reviewers and editors. I am glad to acknowledge their contribution.

\section{References}

Alexander, C. (1979). The timeless way of building. New York: Oxford University Press.

Alexander, C., Ishikawa, S., Silverstein, M., Jacobson, M., Fiksdahl-King, I. \& Angel, S. (1977). A pattern language: Towns, buildings, construction. New York: Oxford University Press.

Avgeriou, P., Papasalouros, A., Retalis, S. \& Skordalakis, E. (2003). Towards a pattern language for learning management systems. Educational Technology $\mathcal{E}$ Society, 6(2), 11-24. http:/ / www.ifets.info/journals /6_2/2.html

Biggs, J. (1999). Teaching for quality learning at university: What the student does. Buckingham: Open University Press.

de Jong, T. \& Sarti, L. (Eds) (1994). Design and production of multimedia and simulationbased learning material. Dordrecht: Kluwer.

Eckstein, J., Marquardt, K., Manns, M. \& Wallingford, E. (2001). Patterns for experiential learning. Paper presented at the EuroPLoP 2001.

Frizell, S., \& Hubscher, R. (2002a). Aligning theory and web-based instructional design practice with design patterns. Paper presented at the World Conference on E-Learning in Corp., Govt., Health. \& Higher Ed. 2002.

Frizell, S., \& Hubscher, R. (2002b). Supporting the application of design patterns in web-course design. Paper presented at the ED-MEDIA 2002, Denver CO.

Gamma, E., Helm, R., Johnson, R. \& Vlissides, J. (1995). Design patterns: Elements of reusable object-oriented software. New York: Addison-Wesley.

Goodyear, P. (1997). Instructional design environments: Methods and tools for the design of complex instructional systems. In S. Dijkstra, N. Seel, F. Schott \& R. Tennyson (Eds), Instructional design: International perspectives (pp. 83-111). Mahwah NJ: Lawrence Erlbaum Associates.

Goodyear, P. (1999). Pedagogical frameworks and action research in open and distance learning. European Journal of Open and Distance Learning. http: / / www.eurodl.org/materials / contrib/1999/goodyear/

Goodyear, P. (2001). Effective networked learning in higher education: Notes and guidelines (Deliverable 9). Bristol: Joint Information Systems Committee (JISC). http: / / csalt.lancs.ac.uk/jisc/docs/Guidelines_final.doc

Goodyear, P. (2002a). Psychological foundations for networked learning. In C. Steeples \& C. Jones (Eds), Networked learning: perspectives and issues (pp. 49-75). London: Springer Verlag.

Goodyear, P. (2002b). Teaching online. In N. Hativa \& P. Goodyear (Eds), Teacher thinking, beliefs and knowledge in higher education (pp. 79-101). Dordrecht: Kluwer Academic Publishers. 
Goodyear, P., Avgeriou, P., Baggetun, R., Bartoluzzi, S., Retalis, S., Ronteltap, F. et al. (2004). Towards a pattern language for networked learning. In S. Banks, P. Goodyear, V. Hodgson, C. Jones, V. Lally, D. McConnell \& C. Steeples (Eds), Networked learning 2004 (pp. 449-455). Lancaster: Lancaster University.

Goodyear, P., Banks, S., Hodgson, V. \& McConnell, D. (2004). Research on networked learning: aims and approaches. In P. Goodyear, S. Banks, V. Hodgson \& D. McConnell (Eds), Advances in research on networked learning. Dordrecht: Kluwer Academic Publishers.

Hara, N. \& Kling, R. (1999). Students' frustrations with a web-based distance education course. First Monday, 4(12). http:/ / www.firstmonday.org/issues/issue4_12/hara/index.html

Hoogveld, A., Paas, F., Jochems, W., \& van Merrienboer, J. (2002). Exploring teachers' instructional design practices from a systems design perspective. Instructional Science, 30, 291-305.

Jonassen, D. (Ed.). (1988). Instructional designs for microcomputer courseware. Hillsdale New Jersey: Lawrence Erlbaum Associates.

Jonassen, D. \& Kwon, H. (2001). Communication patterns in computer-mediated versus face-to-face group problem-solving. Educational Technology Research and Development, 49(1), 35-51.

Jones, C. \& Asensio, M. (2002). Designs for networked learning in higher education: a phenomenographic investigation of practitioners' accounts of design. In C. Steeples \& C. Jones (Eds), Networked learning: perspectives and issues (pp. 253-278). London: Springer Verlag.

Jones, C., Asensio, M. \& Goodyear, P. (2000). Networked learning in higher education: Practitioners' perspectives. Journal of the Association for Learning Technology, 8(2), 18-28. [verified 7 Nov 2004] http: / / domino.lancs.ac.uk/edres/csaltdocs.nsf/By\%20Title/FB33EEA442EDE CD8802568FD0040B9EF / \$FILE/Jones+etal-06-00.doc

Koschmann, T. (1996). Paradigm shifts and instructional technology: an introduction. In T. Koschmann (Ed.), CSCL: Theory and practice of an emerging paradigm (pp. 1-23). Mahwah New Jersey: Lawrence Erlbaum Associates.

Lyardet, F., Rossi, G. \& Schwabe, D. (1998). Using design patterns in educational multimedia applications. Paper presented at the ED-MEDIA '98 Conference.

McConnell, D. (2000). Implementing computer supported cooperative learning (2nd ed.). London: Kogan Page.

Naidu, S. (1993). Instructional systems design - the science of human performance technology. Media and technology for human resource development, 5(3), 197-203.

Oliver, R., Harper, B., Hedberg, J., Wills, S. \& Agostinho, S. (2002). Formalising the description of learning designs. In A. Goody, J. Herrington, \& M. Northcote (Eds.), Quality conversations: Research and Development in Higher Education, Volume 25 (pp. 496-504). Jamison, ACT: HERDSA. http: / / www.ecu.edu.au/conferences/herdsa/main/papers/ref/pdf/Oliver.pdf

Paulsen, M. (1995). The on-line report on pedagogical techniques for computermediated communication. [not found 7 Nov 2004] http:/ / www.nki.no/ morten/ 
Pirolli, P. (1991). Computer-aided instructional design systems. In H. Burns, J. Parlett \& C. Redfield (Eds), Intelligent Tutoring Systems: Evolution in Design (pp. 105-125). Hillsdale New Jersey: Lawrence Erlbaum Associates.

Reigeluth, C. (Ed) (1999). Instructional design theories and models Vol 2: a new paradigm of instructional theory. Mahwah NJ: Lawrence Erlbaum Associates.

Romiszowski, A. \& Mason, R. (2004). Computer-mediated communication. In D. Jonassen (Ed), Handbook of research for educational communications and technology (2nd ed., pp. 397-431). Mahwah NJ: Lawrence Erlbaum.

Salmon, G. (2000). E-moderating: the key to teaching and learning online. London: Kogan Page.

Salmon, G. (2002). E-tivities: The key to active online learning. London: Routledge Falmer.

Spector, M., Polson, M. \& Muraida, D. (Eds) (1993). Automating instructional design: concepts and issues. Englewood Cliffs NJ: Educational Technology Publications.

Stephenson, J. (Ed) (2001). Teaching and learning online: New pedagogies for new technologies. London: Routledge Falmer.

Tennyson, R. (Ed.). (1994). Automating instructional design, development and delivery. Berlin: Springer Verlag.

van Merrienboer, J. (1997). Training complex cognitive skills: A four component instructional design model for technical training. Englewood Cliffs, NJ: Educational Technology Publications.

Wisner, A. (1995). Understanding problem building: Ergonomic work analysis, Ergonomics, 38(3) 595-605.

This article received an Outstanding Paper Award at ASCILITE 2004, gaining the additional recognition of publication of an expanded version in AJET. The reference for the Conference version is:

Goodyear, P. (2004). Patterns, pattern languages and educational design. In R. Atkinson, C. McBeath, D. Jonas-Dwyer \& R. Phillips (Eds), Beyond the comfort zone: Proceedings of the 21st ASCILITE Conference (pp. 339-347). Perth, 5-8 December.

http:/ / www.ascilite.org.au/ conferences / perth04/procs / goodyear.html

Peter Goodyear, Professor of Education

Centre for Research on Computer Supported Learning and Cognition

(CoCo), School of Development and Learning

Education Building (A35), University of Sydney, NSW 2006, Australia

P.Goodyear@edfac.usyd.edu.au

http:/ / coco.edfac.usyd.edu.au/ 